\title{
Rationele extra-eloquente closed-loop corticale stimulatie
}

Epilepsiechirurgie in de sensomotorische cortex is vaak beperkt mogelijk. Slechts $30-72 \%$ van deze patiënten wordt aanvalsvrij en 50\% van deze patiënten krijgt functieverlies na operatie (van Offen et al., 2017). In deze studie wordt de mogelijkheid onderzocht om de aanvalsfrequentie te verminderen door corticale closed-loop elektrostimulatie. Het doel hiervan is om de aanval in een vroeg stadium te stoppen.

\section{REC2Stim-studie}

In de 'Rationele Extra-eloquente Closed-loop Corticale Stimulatie' (REC2Stim) studie wordt bij patiënten met focale epilepsie eerst een intracranieel elektrodengrid geïmplanteerd in de primaire sensomotorische cortex waarmee wordt beoordeeld of het epileptische focus gereseceerd kan worden. Als dit niet mogelijk is, omdat het focus zich in het eloquente sensomotorische gebied bevindt, wordt er een neurostimulator (Activa $\mathrm{PC}+\mathrm{S}$, Medtronic) geïmplanteerd. Dit apparaat wordt klinisch de REC2Stim-fase van negen maanden. Tijdens deze fase wordt in het betreffende corticale gebied elektrisch gestimuleerd zodra er een aanval wordt gedetecteerd en worden de stimulatie parameters verder aangepast om de aanvalsfrequentie te verlagen.

\section{Geïncludeerde patiënten}

In de studie werden tussen november 2019 en oktober 2020 aanvankelijk zeven patiënten geïncludeerd (tabel I). Deze patiënten hadden refractaire focale epilepsie in de

\begin{tabular}{|c|c|c|c|c|}
\hline & Neurostimulator & Leeftijd (jaar) & Geslacht & Betrokken extremiteit \\
\hline REC2StimoI & $\mathrm{Ja}$ & 38 & $\mathrm{~V}$ & Hand R \\
\hline REC2Stimo2 & Nee & 2I & $\mathrm{V}$ & Hand R \\
\hline $\mathrm{REC}_{2} \mathrm{Stimo}_{3}$ & $\mathrm{Ja}$ & 23 & M & Been $\mathrm{R}$ \\
\hline REC2Stimo4 & Nee & 50 & $\mathrm{~V}$ & Mond L \\
\hline REC2Stimo5 & $\mathrm{Ja}$ & 24 & M & Been L \\
\hline REC2Stimo6 & $\mathrm{Ja}$ & $5 \mathrm{I}$ & $\mathrm{V}$ & Been $\mathrm{R}$ \\
\hline REC2Stimo7 & $\mathrm{Ja}$ & 33 & M & Hand L \\
\hline
\end{tabular}

Tabel 1 Karakteristieken van de patiënten die geïncludeerd zijn in de REC2Stim-studie [N.B. V = vrouw, M = man, R = rechts, L = links]

gebruikt voor diepe hersenstimulatie en heeft enerzijds registratie- en analysesoftware, waardoor het aanvalspatronen kan herkennen, en anderzijds een generator voor het toedienen van specifieke stimuli. Van beide delen zijn de parameters afzonderlijk in te stellen. Eén elektrodestrip wordt geplaatst op het epileptische focus en één elektrodestrip wordt geplaatst op een extra-eloquent gebied met een subcorticale netwerkverbinding naar het epileptische focus. Daarna wordt de patiënt een jaar gevolgd. Tijdens de 'data-verzamel-fase' van twaalf weken wordt het intracraniele EEG gemeten tijdens aanvallen, en wordt het aanvalsdetectie-algoritme geoptimaliseerd. Hierna volgt sensomotorische cortex en minimaal twee aanvallen per dag. Twee patiënten (patiënt REC2Stimo2 en patiënt REC2Stimo4) werden geëxcludeerd, omdat voor deze patiënten tijdens de gridregistratie een resectie toch mogelijk bleek te zijn.

\section{Huidige stand van zalken}

Op het moment van schrijven (december 2020) is er een neurostimulator geïmplanteerd bij vijf patiënten (figuur I). De patiënt REC2Stimor heeft gedurende negen maanden na implantatie zes aanvallen gehad. Dit bleek onvoldoende om een patiënt-specifiek detectie algoritme in te stellen. 


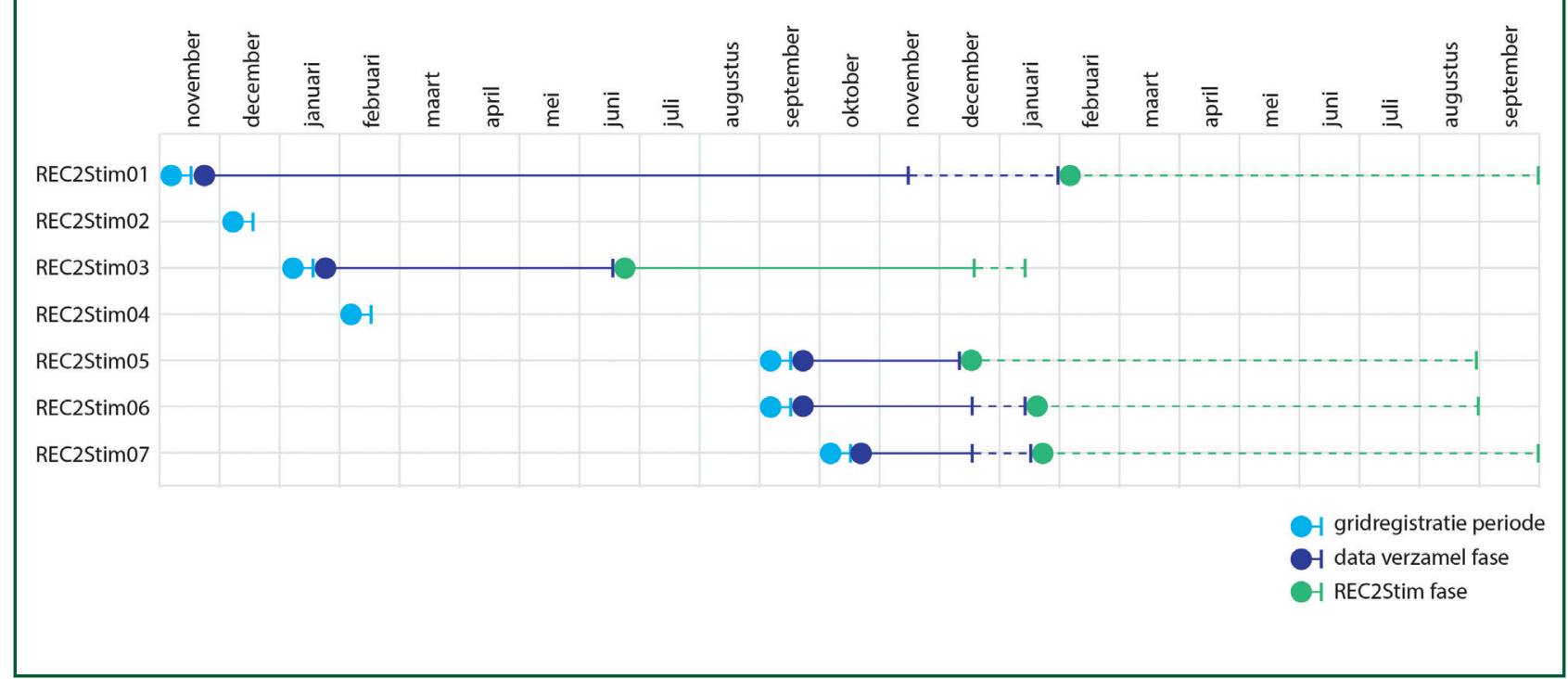

Figuur 1 Tijdlijn waarin de perioden van de gridregistratie, de data-verzamel-fase en de REC2Stim-fase per patiënt zijn weergegeven. De cerste patiënt is in november 2019 geïmplanteerd, de laatste in oktober 2020.

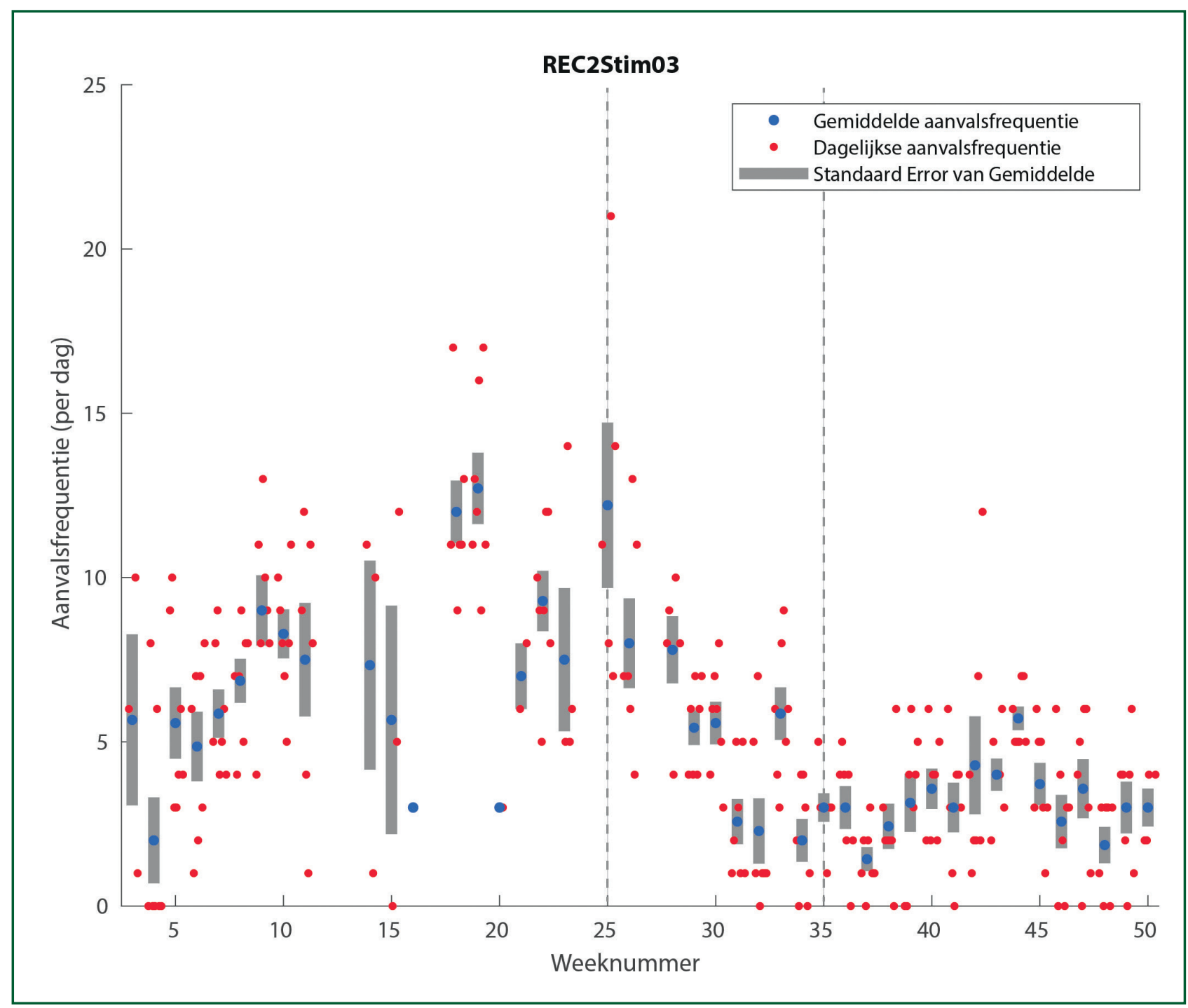

Figuur 2 Aanvalsfrequentie bij patiënt REC2Stimo3 na implantatie van de neurostimulator. De rode punten zijn het aantal aanvallen per dag. De blauwe punten zijn het gemiddelde aantal aanvallen per dag gedurende één week. De grijze balken zijn de standaard errors van het gemiddelde van het aantal aanvallen per dag gedurende één week. 
Sinds oktober 2020 is er een toegenomen aanvalsfrequentie en kan het detectie algoritme worden geoptimaliseerd. Ook patiënt REC2Stimo6 en REC2Stimo7 bevinden zich nog in de 'data-verzamel-fase'. We verwachten in het voorjaar van 202I te starten met de REC2Stim-fase bij de hier genoemde drie patiënten.

\section{Stimulatie}

Bij patiënten REC2Stimo3 en REC2Stimo5 werd een detectie algoritme ingesteld met een goede sensitiviteit (voor beiden $94 \%$ ) en een laag aantal fout-positieven per uur (respectievelijk 3.8/uur en $0.5 /$ uur), gebaseerd op de gerapporteerde aanvallen en de geregistreerde detecties. Bij deze patiënten werd respectievelijk in juni 2020 en in december 2020 gestart met de REC2Stim-fase. In figuur 2 is de aanvalsfrequentie van patiënt $\mathrm{REC}_{2} \mathrm{Stimo}_{3}$ weergegeven gedurende het verloop van de studie. In week 25 werd gestart met stimulatie (zie linker verticale stippellijn). In de eerste pe-riode werd voornamelijk continue gestimuleerd vanwege een effect van stimulatie op detec- tie. Vanaf week 35 (zie rechter verticale stippellijn) werd er alleen gestimuleerd als er een aanval gedetecteerd werd. De patiënt heeft zelf het idee dat stimulatie geen effect heeft op de aanvalsfrequentie. Er is echter vanaf vijf weken na het begin van stimulatie een duidelijke reductie in aanvalsfrequentie. De komende periode worden voor beide patiënten de stimulatie parameters aangepast waarmee naar verwachting de aanvalsfrequentie afneemt.

\section{Perspectief}

De resultaten van deze nieuwe vorm van behandeling zullen in de loop van 202I duidelijk worden. Als ze positief zijn, kunnen meerdere patiënten hiervoor worden geïncludeerd.

\section{Referenties}

van Offen M, van Rijen PC, Leijten FS. (2017) Central lobe epilepsy surgery - (functional) results and how to evaluate them. Epilepsy Res. I30:37-46

\section{Huwelijk van geschuwden:} Onchocerciasis-geassocieerde epilepsie

Is de ernstige epilepsie van kinderen in de dorpen van Tanzania, die vaak diep in de binnenlanden liggen, het gevolg van een parasiet of toch een autoimmuun aandoening? In deze bijdrage een verslag van de mogelijke oorzaken en gevolgen van deze vorm van epilepsie voor de kinderen die hierdoor worden getroffen.

Tanzania, een reisverhaal?

Diep in de binnenlanden van Tanzania ligt het dorp Sali, op drie dagen rijden vanuit Moshi. Een tocht in een grote, oude terreinwagen door een landschap van rode aarde, onder regenaankondigende wolken, langs groepjes Masai en langs ontbottende baobabs. In de jeep zitten drie plaatselijke artsen, onder wie de Nederlandse neurologe Marieke Dekker die al vele jaren in het Kilimanjaro Christian Medical Centre (KCMC) werkt, en drie gasten uit Nederland: een neuroloog, een geneticus en een neuropsycholoog. In
Mahenge, de stad van de geroemde epilepsiekliniek van Louise Jilek-Aall, stapt ook de arts die iedere week in de verspreid liggende dorpen een epilepsiespreekuur houdt in de wagen. De wegen zijn niet verhard, de modder spat hoog op en zakt dan langzaam langs de ramen omlaag. $\mathrm{Na}$ drie dagen van dertien uur rijden komt het dorp in zicht: Sali, een idyllisch klein dorp aan een beekje, huizen omgeven door bananenpalmen, zuurzakbomen en ananasvelden. 